\title{
O comércio de medicamentos de gênero na mídia impressa brasileira: misoprostol e mulheres
}

\author{
The illegal market for gender-related drugs \\ as portrayed in the Brazilian news media: \\ the case of misoprostol and women
}

\author{
1 Anis: Instituto de Bioética, \\ Direitos Humanos e Gênero, \\ Brasília, Brasil. \\ 2 Universidade de Brasília, \\ Brasília, Brasil. \\ Correspondência \\ D. Diniz \\ Anis: Instituto de Bioética, \\ Direitos Humanos e Gênero. \\ C. P. 8011 , Brasília, DF \\ 70673-970, Brasil. \\ anis@anis.org.br
}

\begin{abstract}
This article analyzes how the Brazilian news media covers the illegal market for misoprostol, the main drug used to induce abortion. A total of 1,429 news stories were retrieved from 220 print and electronic media channels from 2004 to 2009. The analysis included 524 stories from 62 regional and national newspapers. Misoprostol appeared repeatedly in the news, but was usually approached from a criminal perspective, unlike abortion as a whole, which the Brazilian media routinely covers as a religious, political, and public health issue. Misoprostol is part of the illegal gender-related drug market, along with drugs for weight loss and erectile dysfunction and anabolic steroids. Sixty-four (12\%) of the news stories told life histories of women who had aborted with misoprostol. The women's ages ranged from 13 to 46 years, and socioeconomic status was associated with different experiences with abortion. Three characters appeared in the women's abortion itineraries: girlfriends (confidantes), go-betweens, and physicians. Stories of late-stage abortion are confused with the criminal characterization of infanticide and provide the extreme cases in the media's narrative on abortion.
\end{abstract}

Induced Abortion; Abortifacient Agents; Misoprostol; News
Debora Diniz 1,2

Rosana Castro 1,2

\section{Introdução}

O aborto é um dos temas que provoca o funcionamento dos dispositivos narrativos e de agendamento das mídias. Entendido como um caso típico que estimula o acionamento de ferramentas de produção de notícias, o aborto não deixou de ser objeto de estudo e análise mesmo em países onde é autorizado em lei 1,2,3,4. Por se manter como uma questão que provoca a política, a religião e as relações de gênero, o aborto é pauta permanente de grande parte da cobertura da imprensa internacional e brasileira. O potencial de repercussão desse tema na mídia é também o que provoca o ethos das práticas e valores das comunidades de jornalistas para a divulgação de uma notícia 5. Discute-se o aborto à luz de análises de enquadramento, de definição de agenda, de viés narrativo, ou mesmo de tendências ideológicas e das linhas editoriais dos veículos, além dos erros de informação $6,7,8$.

No Brasil, a abordagem e o enquadramento do aborto nos meios de comunicação de massa partem de um marco religioso-penal específico: por um lado, o aborto provocado é crime; por outro, é um tema de forte interesse da moral católica. Esse plano de fundo cultural se reflete na forma como as mídias decidem seus critérios de agendamento e enquadramento das notícias: $o$ aborto se vê reduzido a um dilema moral entre duas comunidades incomensuráveis 9,10,11. 
Momentos políticos específicos provocaram fissuras nesse modelo de representação do aborto nos meios de comunicação no Brasil na última década, entre eles, a ação sobre anencefalia no Supremo Tribunal Federal, a descoberta de uma clínica ilegal de aborto no Mato Grosso do Sul e, mais recentemente, o aborto legal de uma menina vítima de estupro 12,13,14. No entanto, mesmo com as particularidades ditadas por cada evento na imprensa, a matriz de enquadramento do aborto como um dilema moral ainda é hegemônica entre as estratégias narrativas utilizadas para descrevê-lo.

Em um contexto de ilegalidade do aborto e de fortalecimento das formas de punição às mulheres que o realizam, os meios de comunicação, sobretudo a imprensa, são um espaço estratégico para a recuperação de informações sobre práticas e redes de aborto ilegal. São escassos os estudos acadêmicos sobre mulheres que realizaram aborto em condições ilegais, uma realidade descortinada preferencialmente pelas notícias 15. Uma possível explicação para esse descompasso entre a pesquisa acadêmica e a investigação jornalística é que, diferentemente do pesquisador, o jornalista tem acesso às histórias dos personagens envolvidos sob a proteção legal do sigilo da fonte. Um pesquisador que estude aborto se compromete, individualmente e diante de um comitê de ética em pesquisa, a garantir o sigilo e anonimato dos dados ou a mantê-los em regime de confidencialidade, mas, infelizmente, sem nenhuma proteção legal para esses acordos de pesquisa 16. Como uma medida de cautela, praticamente inexistem pesquisas etnográficas ou com outras metodologias qualitativas sobre mulheres que abortam em clínicas privadas ilegais. Grande parte dos estudos acadêmicos brasileiros sobre esse tema foi realizada por profissionais de saúde em hospitais públicos com mulheres em processo de abortamento iniciado por medicamentos 15 .

O aborto por medicamentos (medical abortion) provocou uma mudança no perfil de morbimortalidade por aborto inseguro no Brasil e internacionalmente $17,18,19,20,21$. Os primeiros estudos brasileiros sobre o uso do misoprostol para a indução do aborto datam do início dos anos 1990, momento em que a venda do Cytotec, principal nome comercial da droga, foi proibida pela Agência Nacional de Vigilância Sanitária (ANVISA), sendo autorizada apenas para fins de tratamento da úlcera gástrica 22 . Desde então, pouco se conhece sobre as práticas e rotinas das mulheres que abortam por medicamento no Brasil, embora, ao mesmo tempo, o aborto medicamentoso seja o principal método de aborto seguro em países onde é autorizado 23,24,25,26.
O aborto por medicamentos é considerado ilegal no Brasil, sendo apenas autorizado em programas de aborto legal. Os principais medicamentos para indução de aborto são o misoprostol e a ocitocina, porém com restrição de venda pelas farmácias 27 . Muito embora ambos sejam utilizados pelos serviços de aborto legal, o comércio ilegal de medicamentos para o aborto é majoritariamente de misoprostol 28. Este artigo analisa como a mídia impressa brasileira noticia o comércio do misoprostol, o principal medicamento utilizado para provocar o aborto. $\mathrm{O}$ objetivo é descrever o contexto em que o aborto ilegal por medicamentos se encontra no Brasil e recuperar histórias de mulheres que abortaram utilizando este método.

\section{Metodologia}

A pesquisa empírica foi realizada em uma base de monitoramento de 662 notícias produzidas por veículos de mídia impressa e eletrônica: 14 matérias publicadas em veículos de mídia impressa nacional, 73 em veículos de mídia impressa regional, 4 em revistas nacionais e 571 veiculadas exclusivamente em suporte eletrônico. A classificação como veículo nacional e regional é utilizada pela base de monitoramento das mídias onde foi realizada a pesquisa e se fundamenta nos critérios de circulação do jornal fora do estado em que é produzido e pela prioridade de pauta para as matérias, se nacional ou regional. As palavras-chave de busca foram misoprostol, citotec e cytotec, o que resultou em 220 veículos e 1.429 notícias, sem exclusão dos casos de notícia por repetição entre os diferentes veículos. A extensão das notícias variou de 210 caracteres a 22.669 caracteres entre os jornais impressos nacionais e regionais, e de 3.492 caracteres a 27.153 caracteres nas revistas impressas nacionais. Foram incluídas reportagens, editoriais e artigos de opinião. A pesquisa recuperou notícias entre janeiro de 2004 e dezembro de 2009.

A inclusão de todos os tipos de veículos e suportes produtores de notícias (impressos e eletrônicos) provocou uma maior freqüência de matérias publicadas em mídias exclusivamente online. No entanto, como grande parte das notícias era simples reproduções de boletins policiais, replique de matérias de agências de notícias ou de jornais impressos de circulação regional ou nacional, os dados ganhavam uma magnitude que pouco antecipava as questões relacionadas ao conteúdo discursivo sobre o misoprostol nos meios de comunicação no Brasil. Por isso, a análise em profundidade dos dados foi efetuada em um universo de 60 jornais impressos, sendo 8 na- 
cionais e 52 regionais, e 4 revistas nacionais impressas, em um total de 532 notícias, excetuandose os veículos exclusivamente online (Tabela 1). A decisão de incluir os jornais regionais se deu pela freqüência do misoprostol nessas mídias, além do fato de esse duplo universo discursivo permitir a avaliação comparativa das estratégias de enquadramento locais ou nacionais sobre o misoprostol.
Os dados foram recuperados e analisados por meio de técnicas seqüenciais de pesquisa. A primeira fase, quantitativa, traçou um mapa nacional de como se apresenta o misoprostol na mídia impressa brasileira. As 524 notícias foram lidas e classificadas por duas pesquisadoras independentes, a partir de um glossário de termos e de um instrumento de registro dos dados. O instrumento estruturado foi composto de seis quesitos,

Tabela 1

Freqüência das notícias por ano e veículo - mídias impressas nacionais e regionais, 2004-2009.

\begin{tabular}{|c|c|c|c|c|c|c|c|c|c|c|c|c|c|}
\hline \multirow[t]{2}{*}{ Veículo } & \multirow[t]{2}{*}{ Local } & \multicolumn{2}{|c|}{2004} & \multicolumn{2}{|c|}{2005} & \multicolumn{2}{|c|}{2006} & \multicolumn{2}{|c|}{2007} & \multicolumn{2}{|c|}{2008} & \multicolumn{2}{|c|}{2009} \\
\hline & & $\%$ & $\mathbf{n}$ & $\%$ & $\mathbf{n}$ & $\%$ & $\mathbf{n}$ & $\%$ & n & $\%$ & $\mathbf{n}$ & $\%$ & $\mathrm{n}$ \\
\hline A Crítica & AM & 3,0 & 2 & 0,0 & 0 & 0,0 & 0 & 0,0 & 0 & 0,0 & 0 & 0,0 & 0 \\
\hline A Gazeta & ES & 0,0 & 0 & 0,0 & 0 & 1,0 & 1 & 5,7 & 5 & 1,1 & 1 & 1,8 & 2 \\
\hline A Gazeta & MT & 10,6 & 7 & 4,1 & 3 & 5,1 & 5 & 5,7 & 5 & 2,3 & 2 & 6,3 & 7 \\
\hline A Notícia & $\mathrm{SC}$ & 1,5 & 1 & 4,1 & 3 & 2,0 & 2 & 1,1 & 1 & 1,1 & 1 & 0,9 & 1 \\
\hline A Tarde & BA & 3,0 & 2 & 4,1 & 3 & 1,0 & 1 & 4,6 & 4 & 4,6 & 4 & 2,7 & 3 \\
\hline A Tribuna & $\mathrm{AC}$ & 0,0 & 0 & 1,4 & 1 & 0,0 & 0 & 1,1 & 1 & 0,0 & 0 & 0,9 & 1 \\
\hline Correio Braziliense & DF & 1,5 & 1 & 12,2 & 9 & 4,0 & 4 & 1,1 & 1 & 5,7 & 5 & 4,5 & 5 \\
\hline Correio da Bahia & BA & 1,5 & 1 & 0,0 & 0 & 3,0 & 3 & 4,6 & 4 & 4,6 & 4 & 0,0 & 0 \\
\hline Correio da Paraíba & $\mathrm{PB}$ & 0,0 & 0 & 1,4 & 1 & 1,0 & 1 & 2,3 & 2 & 2,3 & 2 & 0,0 & 0 \\
\hline Correio de Sergipe & SE & 4,5 & 3 & 2,7 & 2 & 1,0 & 1 & 0,0 & 0 & 0,0 & 0 & 0,9 & 1 \\
\hline Correio do Estado & MS & 1,5 & 1 & 0,0 & 0 & 3,0 & 3 & 3,4 & 3 & 1,1 & 1 & 0,0 & 0 \\
\hline Correio do Povo & RS & 1,5 & 1 & 0,0 & 0 & 0,0 & 0 & 1,1 & 1 & 1,1 & 1 & 0,9 & 1 \\
\hline Diário Catarinense & $\mathrm{SC}$ & 16,7 & 11 & 2,7 & 2 & 1,0 & 1 & 1,1 & 1 & 4,6 & 4 & 2,7 & 3 \\
\hline Diário da Manhã & GO & 3,0 & 2 & 0,0 & 0 & 6,1 & 6 & 1,1 & 1 & 0,0 & 0 & 4,5 & 5 \\
\hline Diário de Natal & $\mathrm{RN}$ & 1,5 & 1 & 1,4 & 1 & 0,0 & 0 & 0,0 & 0 & 0,0 & 0 & 0,0 & 0 \\
\hline Diário de Pernambuco & $\mathrm{PE}$ & 3,0 & 2 & 2,7 & 2 & 2,0 & 2 & 2,3 & 2 & 2,3 & 2 & 1,8 & 2 \\
\hline Diário de Santa Maria & RS & 0,0 & 0 & 1,4 & 1 & 0,0 & 0 & 4,6 & 4 & 1,1 & 1 & 0,0 & 0 \\
\hline Diário do Nordeste & CE & 0,0 & 0 & 13,5 & 10 & 2,0 & 2 & 0,0 & 0 & 2,3 & 2 & 0,0 & 0 \\
\hline Diário do Pará & PA & 0,0 & 0 & 2,7 & 2 & 1,0 & 1 & 1,1 & 1 & 0,0 & 0 & 0,0 & 0 \\
\hline Diário do Povo & $\mathrm{PI}$ & 0,0 & 0 & 1,4 & 1 & 0,0 & 0 & 0,0 & 0 & 1,1 & 1 & 0,0 & 0 \\
\hline Diário Gaúcho & RS & 0,0 & 0 & 0,0 & 0 & 0,0 & 0 & 2,3 & 2 & 0,0 & 0 & 0,9 & 1 \\
\hline Estado de Minas & MG & 0,0 & 0 & 4,1 & 3 & 3,0 & 3 & 2,3 & 2 & 0,0 & 0 & 7,2 & 8 \\
\hline Extra & RJ & 0,0 & 0 & 0,0 & 0 & 0,0 & 0 & 0,0 & 0 & 2,3 & 2 & 0,0 & 0 \\
\hline Folha de Boa Vista & $\mathrm{RR}$ & 4,5 & 3 & 0,0 & 0 & 4,0 & 4 & 2,3 & 2 & 3,4 & 3 & 4,5 & 5 \\
\hline Folha de Rondônia & $\mathrm{RO}$ & 0,0 & 0 & 1,4 & 1 & 1,0 & 1 & 1,1 & 1 & 0,0 & 0 & 1,8 & 2 \\
\hline Folha de S. Paulo & $\mathrm{SP}$ & 6,1 & 4 & 12,2 & 9 & 4,0 & 4 & 4,6 & 4 & 2,3 & 2 & 0,0 & 0 \\
\hline Folha do Estado do Mato Grosso & $\mathrm{MT}$ & 1,5 & 1 & 0,0 & 0 & 1,0 & 1 & 0,0 & 0 & 0,0 & 0 & 0,0 & 0 \\
\hline Gazeta de Alagoas & $\mathrm{AL}$ & 0,0 & 0 & 0,0 & 0 & 0,0 & 0 & 0,0 & 0 & 1,1 & 1 & 0,9 & 1 \\
\hline Gazeta do Povo & $\mathrm{PR}$ & 3,0 & 2 & 0,0 & 0 & 2,0 & 2 & 2,3 & 2 & 3,4 & 3 & 4,5 & 5 \\
\hline Gazeta Mercantil & $\mathrm{SP}$ & 0,0 & 0 & 0,0 & 0 & 0,0 & 0 & 0,0 & 0 & 0,0 & 0 & 0,9 & 1 \\
\hline Hoje em Dia & MG & 0,0 & 0 & 0,0 & 0 & 0,0 & 0 & 5,7 & 5 & 2,3 & 2 & 2,7 & 3 \\
\hline Jornal da Cidade & $\mathrm{SE}$ & 6,1 & 4 & 0,0 & 0 & 7,1 & 7 & 1,1 & 1 & 4,6 & 4 & 7,2 & 8 \\
\hline Jornal da Paraíba & PB & 0,0 & 0 & 0,0 & 0 & 3,0 & 3 & 0,0 & 0 & 3,4 & 3 & 0,0 & 0 \\
\hline Jornal da Tarde & $\mathrm{SP}$ & 0,0 & 0 & 0,0 & 0 & 1,0 & 1 & 3,4 & 3 & 0,0 & 0 & 2,7 & 3 \\
\hline Jornal de Brasília & DF & 4,5 & 3 & 2,7 & 2 & 6,1 & 6 & 0,0 & 0 & 5,7 & 5 & 0,0 & 0 \\
\hline Jornal de Santa Catarina & $\mathrm{SC}$ & 0,0 & 0 & 0,0 & 0 & 1,0 & 1 & 1,1 & 1 & 0,0 & 0 & 2,7 & 3 \\
\hline Jornal do Brasil & RJ & 1,5 & 1 & 0,0 & 0 & 1,0 & 1 & 0,0 & 0 & 1,1 & 1 & 4,5 & 5 \\
\hline
\end{tabular}

(continua) 


\begin{tabular}{|c|c|c|c|c|c|c|c|c|c|c|c|c|c|}
\hline \multirow[t]{2}{*}{ Veículo } & \multirow[t]{2}{*}{ Local } & \multicolumn{2}{|c|}{2004} & \multicolumn{2}{|c|}{2005} & \multicolumn{2}{|c|}{2006} & \multicolumn{2}{|c|}{2007} & \multicolumn{2}{|c|}{2008} & \multicolumn{2}{|c|}{2009} \\
\hline & & $\%$ & $\mathrm{n}$ & $\%$ & $\mathrm{n}$ & $\%$ & $\mathrm{n}$ & $\%$ & $\mathrm{n}$ & $\%$ & $\mathrm{n}$ & $\%$ & $\mathrm{n}$ \\
\hline Jornal do Commercio & PE & 0,0 & 0 & 5,4 & 4 & 3,0 & 3 & 0,0 & 0 & 5,7 & 5 & 0,9 & 1 \\
\hline Jornal do Commercio & RJ & 0,0 & 0 & 0,0 & 0 & 1,0 & 1 & 2,3 & 2 & 1,1 & 1 & 0,0 & 0 \\
\hline Jornal do Dia & $\mathrm{AP}$ & 0,0 & 0 & 0,0 & 0 & 1,0 & 1 & 0,0 & 0 & 2,3 & 2 & 0,9 & 1 \\
\hline Jornal do Senado & $\mathrm{BR}$ & 0,0 & 0 & 0,0 & 0 & 1,0 & 1 & 0,0 & 0 & 0,0 & 0 & 0,0 & 0 \\
\hline Jornal do Tocantins & TO & 0,0 & 0 & 1,4 & 1 & 2,0 & 2 & 0,0 & 0 & 0,0 & 0 & 0,9 & 1 \\
\hline Meio Norte & $\mathrm{Pl}$ & 4,5 & 3 & 1,4 & 1 & 2,0 & 2 & 0,0 & 0 & 0,0 & 0 & 2,7 & 3 \\
\hline O Dia & RJ & 0,0 & 0 & 0,0 & 0 & 0,0 & 0 & 0,0 & 0 & 2,3 & 2 & 4,5 & 5 \\
\hline O Documento & MT & 0,0 & 0 & 2,7 & 2 & 0,0 & 0 & 1,1 & 1 & 0,0 & 0 & 2,7 & 3 \\
\hline O Estadão do Norte & $\mathrm{RO}$ & 3,0 & 2 & 1,4 & 1 & 0,0 & 0 & 0,0 & 0 & 0,0 & 0 & 0,0 & 0 \\
\hline O Estado de S. Paulo & SP & 1,5 & 1 & 2,7 & 2 & 3,0 & 3 & 6,9 & 6 & 2,3 & 2 & 4,5 & 5 \\
\hline O Estado do Maranhão & MA & 1,5 & 1 & 0,0 & 0 & 5,1 & 5 & 1,1 & 1 & 0,0 & 0 & 0,9 & 1 \\
\hline O Estado do Paraná & $P R$ & 3,0 & 2 & 2,7 & 2 & 1,0 & 1 & 2,3 & 2 & 1,1 & 1 & 0,9 & 1 \\
\hline O Globo & RJ & 0,0 & 0 & 0,0 & 0 & 2,0 & 2 & 8,0 & 7 & 6,9 & 6 & 3,6 & 4 \\
\hline O Imparcial & MA & 0,0 & 0 & 1,4 & 1 & 0,0 & 0 & 0,0 & 0 & 0,0 & 0 & 0,9 & 1 \\
\hline O Liberal & PA & 0,0 & 0 & 1,4 & 1 & 4,0 & 4 & 3,4 & 3 & 3,4 & 3 & 0,0 & 0 \\
\hline O Popular & GO & 3,0 & 2 & 0,0 & 0 & 5,1 & 5 & 3,4 & 3 & 1,1 & 1 & 3,6 & 4 \\
\hline O Povo & CE & 0,0 & 0 & 0,0 & 0 & 0,0 & 0 & 1,1 & 1 & 1,1 & 1 & 0,9 & 1 \\
\hline Revista Carta Capital & $\mathrm{BR}$ & 0,0 & 0 & 1,4 & 1 & 0,0 & 0 & 0,0 & 0 & 1,1 & 1 & 0,0 & 0 \\
\hline Revista Época & $\mathrm{BR}$ & 0,0 & 0 & 0,0 & 0 & 0,0 & 0 & 1,1 & 1 & 1,1 & 1 & 0,0 & 0 \\
\hline Revista Isto É & $\mathrm{BR}$ & 1,5 & 1 & 0,0 & 0 & 0,0 & 0 & 0,0 & 0 & 0,0 & 0 & 1,8 & 2 \\
\hline Revista Veja & $\mathrm{BR}$ & 1,5 & 1 & 0,0 & 0 & 0,0 & 0 & 0,0 & 0 & 1,1 & 1 & 0,9 & 1 \\
\hline Tribuna da Imprensa & RJ & 0,0 & 0 & 1,4 & 1 & 2,0 & 2 & 0,0 & 0 & 0,0 & 0 & 0,0 & 0 \\
\hline Tribuna do Norte & $\mathrm{RN}$ & 0,0 & 0 & 0,0 & 0 & 0,0 & 0 & 0,0 & 0 & 1,1 & 1 & 0,0 & 0 \\
\hline Valor Econômico & $\mathrm{SP}$ & 0,0 & 0 & 0,0 & 0 & 0,0 & 0 & 1,1 & 1 & 0,0 & 0 & 0,9 & 1 \\
\hline Zero Hora & RS & 0,0 & 0 & 1,4 & 1 & 0,0 & 0 & 0,0 & 0 & 2,3 & 2 & 0,0 & 0 \\
\hline Total & & & 66 & & 74 & & 99 & & 87 & & 87 & & 111 \\
\hline
\end{tabular}

AC: Acre; AL: Alagoas; AM: Amazonas; AP: Amapá; BA: Bahia; BR: Brasil (circulação nacional); CE: Ceará; DF: Distrito Federal; ES: Espírito Santo; GO: Goiás; MA: Maranhão; MG: Minas Gerais; MS: Mato Grosso do Sul; MT: Mato Grosso; PA: Pará; PB: Paraíba; PE: Pernambuco; PI: Piauí; PR: Paraná; RJ: Rio de Janeiro; RN: Rio Grande do Norte; RO: Rondônia; RR: Roraima; RS: Rio Grande do Sul; SC: Santa Catarina; SE: Sergipe; SP: São Paulo; TO: Tocantins.

Fonte: Anis: Instituto de Bioética, Direitos Humanos e Gênero 35.

que registrou informações sobre o objeto da notícia, outros medicamentos e itens apreendidos com o misoprostol, vendedores e compradores, agentes sociais de controle e fiscalização, formas de denúncia, local de apreensão e histórias de vida. A segunda fase, qualitativa, analisou em profundidade o universo das notícias classificadas como histórias de vida, isto é, notícias da mídia impressa em que biografias de mulheres usuárias do misoprostol foram apresentadas. Foram recuperadas 76 notícias (14\%) com histórias de vida, mas para o estudo de caso em profundidade foram excluídas as repetidas, o que resultou em 64 notícias (12\%) analisadas.

\section{O misoprostol na imprensa brasileira}

O misoprostol entrou no Brasil em 1986, tendo recomendação terapêutica para tratamento de úlcera gástrica. Sua venda livre era permitida nas farmácias até 1991, quando a ANVISA determinou que o medicamento fosse retirado de circulação devido a seu uso clandestino como abortivo 22. Atualmente, é reconhecido tanto pela Organização Mundial da Saúde (OMS) quanto pela ANVISA como princípio ativo com indicação terapêutica de uso obstétrico, com eficácia e segurança comprovadas para provocar aborto até a décima segunda semana de gestação. A legislação atual proíbe tanto sua comercialização quanto seu uso fora de hospitais credenciados junto às autoridades sanitárias e sua propaganda publicitária em meio impresso ou virtual 29,30. O exercício de atividades comerciais ilegais envolvendo o misoprostol insere um novo personagem 
na narrativa midiática sobre o tema do aborto, a saber, a polícia.

O misoprostol não compartilha do enquadramento dado ao aborto pela mídia impressa brasileira 31,32 . É objeto de notícia policial, cujo enquadramento é a venda e o tráfico de medicamentos de gênero (42\%). Há um cardápio de medicamentos no qual o misoprostol é uma peça acessória: são os medicamentos para as mudanças corporais segundo as ordens estéticas e normativas de gênero, tais como os para disfunção erétil ou para emagrecimento. Essas substâncias têm sua eficácia orientada à adequação do corpo de quem as consome a horizontes simbólicos de gênero socialmente prestigiados. A motivação para as investigações policiais não é o tráfico do misoprostol, mas a vigilância ao crescente mercado ilegal de medicamentos de gênero. Diferentemente do misoprostol, que possui registro na ANVISA, é reconhecido pela OMS como medicamento essencial e tem seu uso indicado para aborto em centros de referência do Sistema Único de Saúde (SUS), os outros medicamentos geralmente não têm eficácia comprovada para os fins oferecidos pelo tráfico ou não são registrados no país $23,33,34$.

Os personagens das notícias são as organizações policiais e de vigilância sanitária, e a tônica narrativa são os boletins de investigação policial - mercadoria apreendida, local da operação e perfil dos vendedores. É das bordas das narrativas policiais reproduzidas na mídia impressa que cerca de metade das notícias menciona a figura dos vendedores de misoprostol - um comprimido custa, em média, $R$ \$ 50,00. O ambulante, também apresentado como funcionário de farmácia, ex-funcionário de farmácia ou farmacêutico, é o principal vendedor de misoprostol no universo das notícias. Entre esses tipos e a figura do traficante de medicamentos há uma tênue fronteira na classificação policial, pois são personagens classificados ora pelo ambiente em que comercializam os medicamentos (se na comunidade ou pela Internet), ora pela maior ou menor inserção no mercado de medicamentos de gênero.

Os vendedores são majoritariamente homens (226 homens e uma mulher). Eles se apresentam sob duas figuras muito diferentes que antecipam suas inserções no mercado ilegal de medicamentos de gênero. A primeira e mais comum é a do intermediário na circulação do medicamento. Sua biografia típica é a de um indivíduo da comunidade, que trabalha sem armas e sem conexão com o tráfico de entorpecentes. Em geral é pego em flagrante após investigação policial ou denúncia anônima. É uma pessoa conhecida como vendedor de medicamentos para a sexualidade e para o corpo. Houve casos de flagrante em que anotações sobre o regime de utilização do misoprostol para aborto foram encontradas junto às cartelas dos medicamentos, o que sugere ser também uma atribuição do intermediário informar as mulheres quanto ao uso. O intermediário é o personagem na linha final da transação do medicamento, mas desconhece quem fornece diretamente a droga ou é tão frágil que mantém o sigilo mesmo em risco de prisão.

A segunda figura, mais rara na mídia impressa, é a do fornecedor do medicamento (68 homens). Ele é alguém que possui grandes estoques de medicamento, atua pela Internet, tem uma lista de clientes e intermediários em todo o país e oferece um cardápio de medicamentos de gênero mais diversificado, muitos dos quais não têm registro na ANVISA para comercialização no país: anabolizantes (Deca-Durabolin), moderadores de apetite (Desobesi-M) e redutores de gordura (Lipostabil), além do misoprostol (Cytotec) e de estimulantes sexuais (Pramil, Cialis ou Eroxil). Não há aproximação direta desse personagem com as mulheres, muito embora ele também possa atuar na transmissão dos saberes e das práticas sobre como usar o misoprostol para aborto. Ao que parece, no entanto, seu principal ramo do mercado consiste em outros itens do comércio ilegal de medicamentos de gênero, não sendo o misoprostol o item mais cobiçado.

Para a mídia impressa, o aborto é o uso a que se destina o misoprostol, assim como o Desobesi-M é para emagrecimento e o Pramil, para disfunção erétil. Ao reduzir o misoprostol a um dos produtos do tráfico de medicamentos de gênero, as matérias são peças factuais sobre a ação policial, afastando-se do enquadramento religiosopolítico do aborto na imprensa brasileira. Pouco se sabe sobre os compradores do misoprostol, pois o foco da cobertura é a ação policial, os produtos apreendidos e, em menor intensidade, a figura dos vendedores. As mulheres, exceto nos casos de flagrante, raramente são mencionadas nas matérias. As autoridades discursivas tradicionais sobre aborto - tais como médicos, religiosos e feministas - são também ignoradas, pois as vozes legítimas são as instituições policiais e de fiscalização em saúde pública. Essa ausência pode ser entendida como um indicativo do enquadramento policial do misoprostol.

O circuito narrativo mais comum tem início com uma denúncia de ponto de venda ou uma notícia de apreensão de tráfico de medicamentos. Grande parte das notícias se limita à descrição policial do fenômeno, sendo poucas as que avançam para usos dos medicamentos ou informações sobre vendedores e compradores. As mulheres só aparecem quando há uma inversão de pauta ou enquadramento: a questão cen- 
tral não é a venda ilegal de medicamentos, mas o aborto provocado por eles. É nesse contexto que as 64 notícias com histórias de vida de mulheres que realizaram aborto com misoprostol surgem nas fissuras do enquadramento policial do misoprostol como um produto do mercado de medicamentos de gênero na mídia impressa brasileira.

\section{As mulheres}

São 74 mulheres entre 13 e 46 anos e sua inserção de classe é o principal demarcador biográfico nas matérias. São dois grupos de mulheres, enquadradas em dois perfis econômicos: as mulheres trabalhadoras (60) e as jovens burguesas (14). As mulheres trabalhadoras são empregadas domésticas, com pouca educação formal, já com filhos e cujo companheiro é descrito como alguém em uma relação extraconjugal, alienado pelo alcoolismo ou pelo desemprego. Para elas, o aborto é uma necessidade. As jovens burguesas são estudantes, mulheres descritas como relaxadas com os cuidados reprodutivos, mas cujo apoio familiar as protege com a garantia de realização de um aborto seguro em clínica ilegal ou com a compra de misoprostol de boa qualidade. Para elas, o aborto é um recurso de planejamento reprodutivo.

As instituições policiais alcançam de modo diferente esses dois grupos de mulheres. Não há jovens burguesas algemadas ou torturadas pelos médicos em um hospital público, além do que são as mulheres trabalhadoras as presas por aborto ilegal, confrontadas por júri popular ou indiciadas pelo crime de aborto (18 mulheres). No entanto, mesmo entre o grupo de mulheres trabalhadoras, há dois enquadramentos diferentes, a depender do tempo gestacional em que o aborto foi realizado. As mulheres trabalhadoras que usam o misoprostol e abortam nas primeiras semanas são apresentadas como personagens de uma peça de retórica midiática: suas biografias são protegidas por pseudônimos e atestam a veracidade da voz do jornalista. Já os dez casos de aborto tardio são confundidos com os de infanticídio, provocando uma sobreposição de crimes que silencia as mulheres. Nesses casos, as histórias são sempre enquadradas nos relatos em um contexto de peças policiais sobre crimes violentos.

Há um enredo que se repete em seis veículos regionais com histórias de diferentes mulheres. A mulher em estágios finais da gestação, isto é, entre sete e oito meses de gravidez, provoca a expulsão do feto com dezenas de pílulas de misoprostol, em combinação com chás e outros medicamentos, sendo os de diabetes os mais comuns. Sozinha, ela enterra o feto nos fundos de casa. Um cachorro é o personagem anônimo que o localiza e permite que a polícia descubra o crime de "ocultação de cadáver". Os desfechos dessa lenda policial urbana sobre aborto são variados: há casos de mutilação do feto pelo cachorro, comprovados por fotografias do delegado para fins de confissão e arrependimento da mulher. Mas o desfecho mais comum é a prisão da mulher após denúncia do médico que a atende para curetagem.

Não há precisão conceitual nas narrativas sobre infanticídio. Em oito matérias, confunde-se o aborto tardio, entre cinco e seis meses, com o parto provocado seguido de infanticídio. O uso do misoprostol nessas duas situações faz com que os meios de comunicação classifiquem ambos os cenários como de aborto ilegal, muito embora mencionem a presença do "cadáver" ou do "bebê" para os casos de infanticídio com nascimento de feto vivo, e do "feto" para os casos de aborto tardio. As histórias de mulheres que induzem o parto com misoprostol e cometem o infanticídio são pauta exclusiva e recorrente na imprensa regional, onde o tom é de grave repreensão moral. Essas mulheres têm como destino a prisão ou o tribunal de júri. Não há nenhuma referência a seus contextos de vida de modo a permitir alguma identificação da opinião pública com suas histórias. Elas representam a alteridade-limite: não só negam a maternidade como também cometem o crime mais brutal contra o feminino, o infanticídio.

As vozes concedidas às personagens são o que aproxima as mulheres trabalhadoras das jovens burguesas: ambas mencionam ter sentido desespero e se recusam a descrever suas práticas como "aborto". Elas "desceram a menstruação" ou "tiraram”, mas é aborto o enquadramento penal dado pelos jornalistas, adotando como referência as vozes policiais. O desespero dessas mulheres não está no arrependimento, mas na solidão das dores, no medo do sangramento ou no uso de medicamentos falsificados e sem efeito. Uma matéria relata um caso de mulher que iniciou o aborto com 12 comprimidos de cibalena e chá de canela, seguidos de dez comprimidos de misoprostol. Sem resultado, usou mais chás, garrafadas e outros dez comprimidos para diabetes, o que acabou por provocar uma infecção uterina que exige internação hospitalar. Em 24 casos, o aborto foi finalizado no hospital público. A rotina de uso do misoprostol varia de 4 a 40 comprimidos, em geral acompanhados de outros produtos que, por associação simbólica, teriam poderes abortivos. Esses casos-limite são o gancho para a imprensa apresentar os três personagens que 
auxiliam as mulheres na decisão pelo aborto com medicamentos.

O primeiro desses personagens é o médico, que atua de duas formas para a concretização do aborto. Em uma fase inicial, convencido do potencial do misoprostol para a redução de danos, o médico informa a mulher sobre o aborto com medicamentos. Esse mesmo médico pode ter uma segunda forma de atuação, nos casos em que é ele próprio o agente que finaliza o aborto após o início do sangramento, mas já em um hospital público. O segundo são os intermediários da circulação de medicamentos, descritos como farmacêuticos ou ambulantes. A eles cabe a entrega do misoprostol com instruções básicas de higiene e segurança de uso. O terceiro personagem são as amigas da mulher que aborta. Elas compartilham saberes e rotinas de uso do misoprostol, em conjunto com chás (buchinha, cabacinha, tapete de oxalá, canela), outros medicamentos (para diabetes, cibalena, permanganato), entorpecentes (maconha, cocaína injetada no útero) ou garrafadas. Não há indexadores biográficos ou sociais para o que os relatos da imprensa descrevem como "amigas", exceto quando as histórias de vida são de prostitutas, entre as quais as instruções sobre o aborto com medicamentos fazem parte da rotina de sobrevivência para o comércio do sexo.

As pautas que apresentam as histórias de vida são provocadas por três temas. A primeira, e mais comum, são histórias de mulheres presas por aborto (17 matérias). A segunda é influenciada pelo debate político nacional, e as histórias de vida das mulheres que abortaram são peças da narrativa midiática (13 matérias). A terceira, mais rara, são os casos de estupro e incesto, em que as personagens são meninas no início da adolescência (2 matérias). Nesse último caso, o enquadramento moral das notícias é outro, seja nas mídias nacionais ou estaduais, havendo uma descrição neutra do aborto por medicamentos. O misoprostol é o medicamento que "estimula contrações" ou, como descreve o comércio de medicamentos, simplesmente o recurso médico para abortar de maneira segura. Não se fala em dor ou desespero das mulheres, mas em como o aborto realizado com atenção médica e em ambiente hospitalar é seguro. Os outros temas que provocam as pautas com histórias de vida de mulheres são o debate político no Congresso Nacional (13 matérias), participação dos homens na realização do aborto (7 matérias), morte materna (4 matérias), comércio de Cytotec (10 matérias) e temas genéricos (8 matérias).

\section{Conclusão}

A mídia se apresenta como meio privilegiado de acesso a informações sobre o comércio ilegal de medicamentos de gênero e mais especificamente sobre o uso do misoprostol. Por dispor de meios profissionais e proteção legal para se aproximar do universo do aborto inseguro, por vezes indisponíveis à pesquisa social, a mídia divulga informações que se constituem em fontes valiosas de pesquisa em saúde pública. As pautas policiais e as histórias de vida das mulheres que abortaram descortinam os personagens do itinerário do aborto inseguro no Brasil, seus papéis e os possíveis efeitos de suas ações sobre a saúde das mulheres. A análise da cobertura jornalística permite avanços significativos em campos ainda obscuros sobre a prática do aborto inseguro no Brasil.

Nessa cobertura específica do uso do misoprostol na mídia brasileira percebe-se um deslocamento do tema do aborto com a entrada do medicamento nas práticas abortivas. As matérias abandonam o debate fundamentalmente moral e se concentram em denúncias e apreensões de medicamentos comercializados ilegalmente, tratando os agentes de controle governamental das áreas de segurança pública e vigilância sanitária como as principais fontes e vozes. Esses atores aparecem em ação articulada para a contenção da circulação do misoprostol e de seu uso para o aborto ilegal. O silenciamento de vozes médicas e de movimentos de mulheres, bem como a não divulgação de informações sobre o efeito do misoprostol para a redução da morbimortalidade materna, ocultam a abordagem do aborto seguro como tema de saúde e de direito das mulheres.

As histórias de vida de mulheres que abortaram com medicamentos são ainda pouco conhecidas no universo dos estudos sobre aborto inseguro no Brasil. O comércio ilegal do misoprostol empurra as mulheres para o mercado clandestino de medicamentos, no qual não há qualquer garantia de procedência ou segurança dos produtos. O misoprostol, quando utilizado corretamente e com dosagem adequada, é um meio seguro e eficiente para a realização do aborto. $\mathrm{O}$ registro de dezenas de mulheres com indicação de aborto incompleto pelo uso de medicamentos levanta a hipótese de o quanto o mercado de medicamentos de gênero, e em particular do misoprostol, já pode estar dominado por produtos falsificados.

Dada a inserção policial do misoprostol, a figura do médico assumiu contornos inesperados no campo da saúde pública. Na narrativa das mulheres, o médico tinha posturas localizadas entre o cuidador e o inquisidor, sendo aquele que 
inicialmente protegeu as mulheres, informandoas sobre o uso seguro do misoprostol, mas sendo também quem as denunciou à polícia em contextos de extrema fragilidade. Os relatos de internações que culminaram em denúncias feitas pelos próprios médicos expõem graves violações de princípios éticos fundamentais à saúde pública, como a confidencialidade e o sigilo. Essa postura inquisidora é contrastada à do médico cuidador, que acolhe as mulheres e oferece tratamento isento de julgamento moral, em observância às prerrogativas éticas da saúde pública.

Os relatos de dor, sofrimento, medo e insegurança contribuem para a aproximação analí- tica da experiência das mulheres, dimensão cujo acesso desafia as metodologias da pesquisa social. As narrativas jornalísticas permitem avançar no conhecimento sobre aborto clandestino no país quanto às condições de decisão das mulheres pelo aborto, aos métodos utilizados, às intercorrências dos procedimentos adotados e ao atendimento dispensado nos serviços públicos de saúde. Nesses relatos, no entanto, permanecem silenciadas as biografias dos principais agentes do comércio ilegal de medicamentos e os itinerários das mulheres que, sozinhas, abortaram tardiamente e foram duplamente punidas pelos crimes de aborto e infanticídio.

\section{Resumo}

Este artigo analisa como a mídia impressa brasileira noticia o comércio clandestino do misoprostol, o principal medicamento para aborto. Foram recuperadas 1.429 notícias, de 220 veículos de informação impressos e eletrônicos, entre 2004 e 2009. A análise foi realizada em 524 notícias de 62 veículos impressos regionais e nacionais. O misoprostol é pauta permanente, mas o enquadramento das notícias é policial, diverso do aborto como uma questão religiosa, política e de saúde pública que domina a mídia brasileira. O misoprostol está inserido no mercado ilegal de medicamentos de gênero, tais como os para emagrecimento, disfunção erétil ou anabolizantes. Sessenta e quatro (12\%) notícias impressas apresentam histórias de vida de mulheres que abortaram com o misoprostol. As mulheres têm de 13 a 46 anos e sua inserção de classe demarca diferentes experiências de aborto. Três personagens foram identificados nos itinerários de aborto: amigas, intermediários e médicos. As histórias de aborto tardio são confundidas com a tipificação penal do infanticídio e são casos-limite para a narrativa midiática.

Aborto Induzido; Abortivos; Misoprostol; Notícias

\section{Colaboradores}

As autoras trabalharam nas etapas de concepção da pesquisa e interpretação dos dados qualitativos. D. Diniz foi responsável pela redação do artigo. R. Castro responsabilizou-se pela elaboração das tabelas e pela redação da conclusão. Ambas são responsáveis pela aprovação final da versão a ser publicada.

\section{Agradecimentos}

As autoras agradecem a Angela Freitas, Arryanne Queiroz, Fabiana Paranhos, João Neves, Lívia Barbosa, Marilena Corrêa, Suzanne Serruya, Greice Menezes, Maria Luiza Heilborn, Vanessa Carrião e Wederson Santos pelas contribuições e participações na fase de pesquisa, além da cessão da base de dados pela Fábrica de Idéias. As discussões da Reunião Técnico-Científica sobre o Aborto Medicamentoso no Brasil, promovida pela Comissão de Cidadania e Reprodução, enriqueceram as idéias aqui apresentadas. Ao Conselho Nacional de Desenvolvimento Científico e Tecnológico (Edital MCT/ CNPq/MS-SCTIE-DECIT/CT - Saúde nº. 22/2007 -Saúde da Mulher). 


\section{Referências}

1. Esacove W. Dialogic framing: the framing/counterframing of "partial-birth" abortion. Sociol Inq 2004; 74:70-101.

2. Ferree MM. Resonance and radicalism: feminist framing in the abortion debates of the United States and Germany. AJS 2003; 109:304-44.

3. Rohlinger DA. Friends and foes: media, politics, and tactics in the abortion war. Soc Probl 2006; 53:537-61.

4. Kumara A, Hessinia LH, Mitchell EMH. Conceptualising abortion stigma. Cult Health Sex 2009; 11:625-39.

5. Mouw T, Sobel M. Culture wars and opinion polarization: the case of abortion. AJS 2001; 106:913-43.

6. Rohlinger DA. Framing the abortion debate: organizational resources, media strategies, and movement-countermovement dynamics. Sociol Q 2002; 43:479-507.

7. Woodward KL. What's in a name? The New York Times on "partial-birth" abortion. Notre Dame J Law Ethics Public Policy 2005; 19:427-42.

8. Pruitt SL, Mullen PD. Contraception or abortion? Inaccurate descriptions of emergency contraception in newspaper articles, 1992-2002. Contraception 2005; 71:14-21.

9. Comissão de Cidadania e Reprodução. Olhar sobre a mídia. São Paulo/Belo Horizonte: Comissão de Cidadania e Reprodução/Maza Edições; 2002.

10. Melo J. Aborto na imprensa brasileira. http://www. patriciagalvao.org.br/t14.htm (acessado em 16/ Abr/2010).

11. Almeida LM. Aborto em pauta: informação ainda muito é pouca. http://www.observatorioda imprensa.com.br/artigos.asp?cod=434CID001 (acessado em 16/Abr/2010).

12. De Freitas S. STF libera aborto em caso de anencefalia. Folha de S. Paulo 2004; 2 jul.

13. Pichonelly M. 10 mil suspeitas de aborto podem ser interrogadas. Folha de S. Paulo 2008; 6 abr.

14. Guandaline L. Menina de 9 anos grávida realiza aborto em maternidade do Recife. O Globo 2009; 4 mar.

15. Secretaria de Ciência, Tecnologia e Insumos Estratégicos, Ministério da Saúde. 20 anos de pesquisas sobre aborto no Brasil. Brasília: Ministério da Saúde; 2009.

16. Diniz D, Guerreiro I. Ética na pesquisa social: desafios ao modelo biomédico. Reciis 2008; 2 Suppl 1:78-91.

17. Ferreira RG, Lima EL, Viggiano M, Moreira S, Amaral WN. Mortalidade materna no Estado de Goiás - 1989-1991. J Bras Ginecol 1994; 104:291-3.

18. Andrade A, Guerra M, Andrade G, Araujo D, Souza JP. Mortalidade materna: 75 anos de observações em uma maternidade escola. Rev Bras Ginecol Obstet 2006; 28:380-7.

19. World Health Organization. Unsafe abortion: global and regional estimates of the incidence of unsafe abortion and associated mortality in 2003. $5^{\text {th }}$ Ed. Geneva: World Health Organization; 2007.

20. Harper CC, Blanchard K, Grossman D, Henderson JT, Darney PD. Reducing maternal mortality due to elective abortion: potential impact of misoprostol in low-resource settings. Int J Gynaecol Obstet 2007; 98:66-9.
21. Li YT, Chen TH, Kuo TC. Efficacy of simultaneous use of mifepristone and misoprostol for early abortion. Int J Gynaecol Obstet 2008; 101:301.

22. Barbosa R, Arilha M. A experiência brasileira com o Cytotec. Estudos Feministas 1993; 1:408-17.

23. Organização Mundial da Saúde. Abortamento seguro: orientação técnica e de políticas para os sistemas de saúde. http://www.iwhc.org/storage/ iwhc/documents/abortamento_seguro_cap.1-4. pdf (acessado em 15/Abr/2010).

24. Federação Latino Americana de Sociedades de Obstetrícia e Ginecologia. Uso de misoprostol em obstetrícia e ginecologia. http://www.cemicamp. org.br/Manual_Misoprostol_Portugues.pdf (acessado em 15/Abr/2010).

25. Fernandez MM, Coeytaux F, Ponce de León RG, Harrison DL. Assessing the global availability of misoprostol. Int J Gynaecol Obstet 2009; 105:180-6.

26. International Consortium for Medical Abortion. Medical abortion. http://www.medicalabortion consortium.org/ (acessado em 23/mar/2010).

27. Agência Nacional de Vigilância Sanitária. Resolução 137, de 29 de maio de 2003. http://e-legis. anvisa.gov.br/leisref/public/showAct.php? id=7917\&word=mifepristona (acessado em 15/Abr / 2010).

28. Warriner IK, Shah IH, editors. Preventing unsafe abortion and its consequences: priorities for research and action. New York: Guttmacher Institute; 2006.

29. Agência Nacional de Vigilância Sanitária. Portaria $\mathrm{n}^{\circ}$. 344, de 12 de maio de 1998. http://www.anvisa. gov.br/legis/portarias/344_98.htm (acessado em 15/Abr/2010)

30. Agência Nacional de Vigilância Sanitária. Resolução no. 911, de 24 de março de 2006. http://elegis.anvisa.gov.br/leisref/public/showAct. php?id=21434\&mode=PRINT_VERSION (acessado em 15/Abr/2010).

31. Entman RMF. Toward clarification of a fractured paradigm. J Commun 2003; 43:51-8.

32. Reese $\mathrm{S}$. The framing project: a bridging model for media research revisited. J Commun 2007; 57:14854 .

33. Agência Nacional de Vigilância Sanitária. Resolução RE no. 905, de 21 de junho de 2001. http:// www.anvisa.gov.br/legis/resol/905_01re.htm (acessado em 15/Abr/2010).

34. Área Técnica de Saúde da Mulher, Departamento de Ações Programáticas Estratégicas, Secretaria de Atenção à Saúde, Ministério da Saúde. Atenção humanizada ao abortamento: norma técnica. Brasília: Ministério da Saúde; 2005.

35. Anis: Instituto de Bioética, Direitos Humanos e Gênero. Pesquisa "Quando o aborto se aproxima do tráfico: uma análise da comercialização do misoprostol”. Brasília: Anis: Instituto de Bioética, Direitos Humanos e Gênero; 2010.

Recebido em 27/Abr/2010

Versão final reapresentada em 31/Ago/2010 Aprovado em 15/Out/2010 